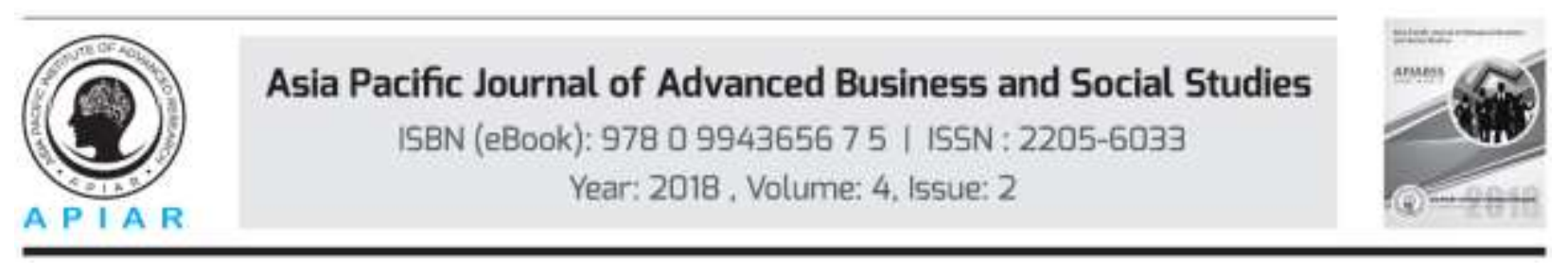

\title{
LINKING CORPORATE SOCIAL RESPONSIBILITY TO ORGANIZATIONAL PERFORMANCE: AN INVESTIGATION OF THE FINANCIAL SECTOR IN PAKISTAN
}

\author{
Dr. Ahmad Raza Bilal \\ Superior University Lahore (Pakistan) \\ Corresponding Email: arb@superior.edu.pk
}

\begin{abstract}
This paper aims to investigate the influence of performance indicators (PIs) on corporate social responsibility (CSR) in banking sector. This novel theoretical conception is investigated through mix methodology technique to find concrete evidences of CSR and its competitive abilities. Results of the study suggested that CSR is positively impacted by ROE, ROD and EPS predictors. Through in-depth interviews, it was surfaced that CSR is in infancy stage in Pakistan and there is a dire need to harmonize society requirements with CSR programs.
\end{abstract}

Keywords: Corporate Social Responsibilities, Return on Equity, Return on Assets, Earning per Share, Return on Deposit, Size, Advances/Deposit Ratio.

\section{Introduction}

Corporate Social Responsibility (CSR) refers to an entity's assurance to be part of continuing economic advancement, joining hands with staff, their family units and masses at large for improved living standards (Srisuphaolarn, 2013).A most important mediator in transformation of society is business for decades. It is pertinent to mention here that an entity's stance may potentially impact on various stakeholders like workers, consumers, shareholders and related public (Ehsan, 2012).

Reportedly, the first researcher who narrated different dimensions of CSR was Howard Bowen also known as the "Father of CSR". CSR for an entity means owning the obligation of organizations decision and dealings to the masses. Requirement of CSR is that organization breaks the usual ambit of conducting business and look ahead from its permissible, technological and economic needs (Noor, 2015).

Investigating and exploring the pros and cons of relationship between CSR and performance indicators (PIs) of the firm has been a long debate since mid-1960s, when Friedman Milton (1962) argued that an entity's social responsibility is to earn profit. His comments made a splash in academic circles as well as in practitioners' community and ignited fire of an intellectual debate on the matter. Efforts were initiated to establish or deny the relationship between CSR and organizational performance. Edwin Locke a renowned organizational logician at Mary Land University also substantiated Friedman argument when he concentrated on the fact that organizations sole responsibility is towards its stockholders. Although various researchers across the globe examined and investigated this relationship, but there is no consensus developed as yet (Mahon, et al., 1997). 
Various approaches related to CSR are being followed globally. Three commonly used approaches are Canadian model, Continental European and Anglo-Saxon. It is commonly known that Chinese consumers perceive a company as socially responsible, which produces secure, premium quality products; German consumers view a company as socially responsible if it provides safe employment; South African customers deem an entity as socially responsible if it makes a constructive role to social requirements like health care and education. Even within the Europe, discussion about CSR is very diverse. Triple Bottom Line (TBL) approach is usually followed in CSR. Core of this concept is People, Planet, and Profit. This structure is used for gauging activities of an entity against economic, ecological and communal factors. In general, CSR is a mean of improving life standard of workers, customers and public at large for common cause of prosperity (Srisuphaolarn, 2013; Ehsan, 2012).

Charity and donations made by entities in Pakistan are generally attributed to factors like tax advantages, marketing tactics, better public image, ethical norms and belief. Charity is a way by which entities contribute to social and economic development. International entities have the largest contribution in canvas of CSR, while local entities are replicating the same, but the pace is quite slow. In Pakistan, CSR is in infancy stage in comparison of developed countries.

The State Bank of Pakistan (SBP) has issued various prudential regulations on different topics including corporate banking. One component of CSR i.e. donations is covered under regulation number G-3 of corporate/commercial banking. The purpose of this regulation is to keep watch on CSR activities, to ensure the management of donations purely on merit based, without nepotism. At the same line, guidelines are presented in the Security and Exchange Commission of Pakistan (SECP's)General Order2009 under section 02 stating that 'Board of Directors are mandated to specify the following: Corporate charity, energy management, ecological fortification events, community venture and wellbeing projects, customer security framework, welfare spending for deprived masses, hiring of handicapped persons, workplace safety and health, business ethics, donations in natural calamities and rural growth plans'.

A few multinational companies operating in Pakistan are spending a stipulated portion of its profit on CSR activities. As far as the banking industry operating in Pakistan is concerned, a gap exists in CSR concept and its practices, which need to be addressed to reap long term advantages of CSR activities. CSR has not been thoroughly researched particularly with reference to Banking Industry of Pakistan. Here in Pakistan, CSR is taken more as an obligation instead of a long-term benefit for the entities and general masses. Therefore, there is a rising need to examine companies' attitude towards CSR, particularly in banking sector of Pakistan (Ehsan, 2012).

The endeavor of this research is to examine whether a relationship exists between PI(s) and CSR in banking industry of Pakistan covering 5 large and 6 medium banks covering financial period of ten years (2004 to 2013). In developed countries, research work on the impact of CSR has been conducted in different outlooks with respect to PI(s) in banking industry. However, this paper is one of the basic studies on assessing the impact of banks' performance indicators on CSR engagement with reference to Pakistani banking sector. To find more reliable results, we conducted quantitative analyses that were revalidated through qualitative approach by conducting semi structured interviews. Further, in most of predominant literature, CSR is taken as predictor; however, we used it as endogenous variable to test the impact of different performance indicators on CSR engagement. 


\section{Literature Review}

Earlier studies did not invest much to investigate the nature of relationship between profitability of financial institutions and CSR, particularly in developing countries. Few studies indicated unstable relations between CSR and financial performance (FP), like the study of Lin(2009) found affirmative relationship between CSR and financial performance (FP) at initial phase of his research; however, when he re-specified the model, impact of CSR found insignificant on FP. The author concluded a possibility for enduring fiscal benefits due to influence of CSR implications.

The CSR practices were assessed by Sweeney (2009), who found a positive relationship among social status, employee magnetism, retention/motivation and loyalty/ consumer desirability. However, PI(s) were not used to assess its impact on CSR. As reported by Surrocaet al. (2010), an affirmative relationship was found between CSR and financial performance in presence of mediating variable i.e. intangible assets in industrial firm; however, they only used performance measure of Tobin's Q and ignored other important performance measures to assess the inclusive profitability.

In a study conducted by Aras (2009), the relationship among CSR, profitability, risk level and firm size was examined. The author found positive relationship between CSR and firm size; however, with financial performance, it was found insignificant. Their study, unfortunately, used different CSR statements published in annual audited accounts, which do not cover all aspects of CSR dimensions and resultantly week gauge of relationship with different profitability indicators like ROA, ROE, ROS etc.

Two dominant approaches for CSR in research literature were either its linkage with external or internal factors. While a few researchers have taken hybrid approach i.e. a combination of both internal and external drivers. Further, in past literature, global factors of CSR and its impact on profitability was mainly tested. In Mexico, a study was conducted to assess the impact of CSR on global factors like management assurance to ethical behavior. It was surfaced that management ethical assurance was positively related with trade related ethics in order to enhance CSR activities (Mullera \& Kolk, 2010). However, proxies taken in this study was subjective in nature\& may not capture the impact on CSR fully.

Yeung (2011) conducted a study to investigate the perception of customers on CSR and banking practice in top banks of Hong Kong. His study helped bankers to understand the concept for advantage of customer and society at large. However, unluckily, resource allocation for the purpose of CSR was not covered in his study. In another study, Soana (2011) investigated the relationship between CSR and FP by measuring CSR through 'ethical rating' and financial performance through 'marketing and accounting ratios'. It was emerged after the detailed analysis that relationship between CSR and FP was insignificant. Unfortunately, her study also used CSR measurement as subjective variable; while variables used for measurement of FP were not directly linked.

CSR motivates business entities to seriously consider its prime obligations towards society in which they function. In the past, Ehsan (2012) conducted a study to investigate the relationship between CSR and financial performance of manufacturing sector in Pakistan. He used different proxies to measure financial performance i.e. ROA, ROE, EPS and FG. Their results indicated affirmative relationship between CSR and Financial Performance. His study, however, was limited owing to use of only four years' financial data from only four manufacturing sectors.

Sarwar (2012) conducted a study on banking sector of Bangladesh to scrutinize the nature of association between CSR and banks' profitability. Against his hypothesis that 'banks having higher high CSR have higher ROE and vice versa' his results could not be statistically proved. Later on, few studies were conducted to define rhetoric of CSR and to find its guiding principles. 
The results of these studies suggested that impact of CSR on profitability may be negative or positive across different industries and it mainly depends on tactical decision-making for CSR activities (Khanifar, et al., 2012).Unfortunately, these studies have also not focused on a particular sector but presented blend of assorted sectors and were mainly used only descriptive analysis.

In recent past, CSR was studied by $\mathrm{Wu}$ and Shen (2013)to test its impact on financial performance using financial data of 162 banks in 22 countries for the period of 10 years. Banks were classified into four groups on the basis of CSR disclosure. His results found that CSR is affirmatively related to FP in terms of ROA, ROE, NII (net interest income), and NnII (noninterest income), but negatively related to NPS (non-performing assets).Entities with high customer awareness were found to have a positive association between CSR and firm value. For entities with less customer awareness, this association was either insignificant or negative. This evidence supported the stance that with certain stipulated conditions, CSR activities may add value to entity (Tamayo, 2013).However, both studies measured CSR protocols from customer's perspective while ignored the employee's perspective.

Another study was conducted by Cyrus (2013) on manufacturing firms enlisted at Nairobi Securities Exchange. His results revealed that CSR practices have a positive relationship with manufacturing effectiveness and capital concentration; however it has insignificant impact on firms' profitability. Additionally, in another, Mushtaq (2013) examined the impact of CSR on employees retention and goodwill of financial institutions in Pakistan. His results concluded a positive influence of CSR on retention of employees and goodwill of banks' employees. Based on his findings, it is inferred that effective and efficient management of fund and exploration of reliable avenues in which its resources were invested to generate the highest income was needed. However, this study was also limited due to small size of reviewed banks; thus, results cannot be generalized for overall financial sector.

In a recent study, Rahman et al.(2014) examined the impact of CSR on banks' profitability. His results postulated insignificant relationship between CSR and profitability; however, based on survey, he suggested that banks should vitally assess its current policy on CSR activities in order to enhance their profitability. Unfortunately, his study was also limited owing to small sample of only one bank from Bangladesh; hence cannot be widespread for all population.

The implementation of CSR protocols in food sector of Pakistan was tested by (Sadiqa, 2014). She used mixed methodology to investigate the impact of CSR on financial performance of food industry. The results of her study have shown positive relationship between CSR and FP in terms of ROE, ROA and EPS. She suggested in her findings that entities by engaging in positive social activities attract more customers which in turn enhance their profitability. However, her sample size was also small and results were limited to food sector only.

CSR in banks and its effect on FP in perspective of financial crisis has also been studied by few researchers. In general, they recommended that large sized banks constantly have greater CSR strengths and issues. Additionally, higher profitable institutions must have to maintain higher capital adequacy requirements (CAR) and fewer charges on deposits, and to compliance CSR requirements, have to hire female and minority directors in their BOD. On the contrary, in most of the studies on low-profit generating banks, a significant relationship is found between CSR and bank distinctiveness. Therefore, the large-sized banks appear to be compensated for CSR and size (Cornett, 2014).CSR has also been studied in terms of public and private status of an entity by Singh and Ahmad (2015). His results indicated that banks in different status, have varying CSR policies and implementation status in general. 
In light of existing literature, it was surfaced that research work on impact of CSR has been conducted in different outlooks with respect to performance in banking industry globally. But, most the studies are limited due to sample size, CSR proxies, use of isolate performance indicators and single testing methodology. Moreover, in past studies, CSR is used as predictor to test its impact on different organizational functions and responsibilities. On the contrary, in current study, we used different performance indicators i.e. ROA, ROE, ROD, EPS and A/D ratios as predictors to examine their impact on CSR engagement with large sample size to more generalize results.

\section{Data Collection and Methodology}

We used mixed methodology approach in which quantitative data were obtained through selfadministered questionnaires and annual audited financial statement; while qualitative data obtained through personal interviews. The sample was comprised of 11 banks (6 large and 5 medium banks) based on banks' asset size. For quantitative research, six different performance indicators were used out of which, five were financial performance indicators namely ROA, ROE, ROD, EPS, Size while one was from liquidity performance namely A/D ratio. Financial data were gathered from banks' published audited financials for the period of 10 years (2004 to 2013). For validation of results, semi structured interviews with managers and senior professionals of sampled commercial banks were conducted. These in-depth interviews were arranged with core objective of having thorough insight on executives' views regarding CSR engagement, and how it influence from selected banks' performance indicators. Views captured through interviews helped us to develop an understanding on how executives perceive the role and impact of financial indicators on CSR. Main idea of interview questions was adopted from Kim(2012) to examine different dimension of CSR. Fourteen extensive, open ended questions directed the interview conducted by the authors(interviewees) with personal meetings for 30 to 40minutes in duration.

Dependent Variable: To test the economic reciprocity of different performance indicators on CSR engagement, we used CSR as dependent variable that was defined as 'obligation of an entity to carry out activities that help to promote and improve the community well-being, caring the environment, employees and different stakeholders including but not limited to community groups, customer, directors, shareholders, suppliers, regulatory bodies and governments ahead of their authorized and economic obligations'. Thus, CSR was a comprehensive and complex construct and various aspects were used for its dimensional measurement. Two main dimensions were used to measure the proxy of CSR i.e. Donations and Employee Welfare Fund. While reviewing literature on CSR and FP relationship, many researchers have been used proxy of Donations for CSR(Lin, 2009; Malik,2014;Singh and Ahmed, 2015).In case of Pakistan, probably each and every bank communicate their assorted social activities like charity, HIV Aids, environmental protection ventures, health, education, skill development programs for youth under the head of donations. The data for this proxyis accessible from audited financial reports as well as the websites of banks. Further, as required under the Companies Ordinance 1984, part III, E-1 of schedule 4; Regulator agency of listed companies 'Securities and Exchange Commission of Pakistan (SECP)'has made it mandatory for all registered entities to declare their spending under the head of corporate donations in the profit and loss statements. Care and concern for employees by the corporation was another dimension widely used for CSR. Most of the firms used worker welfare as proxy for CSR (Cox, 2004; Scholtens, 2008; Muller, 2010). Additionally, under the Worker's Welfare Fund Ordinance (WWF) 1971; organizations have been mandated to disclose their contributions toward worker welfare in their annual reports. Following existing literature, we used both proxies i.e. donations and worker's welfare fund to measure the CSR (Makki, 2008; Lin, 2009; Ehsan, 2012). Ahybrid measure of CSR was developed as follows: 
CSR $=$ Donations + Worker's Welfare Fund $/$ Earnings before Tax

.(Ehsan, 2012)

Independent Variable: Based on literature, most persuasive predictors were chosen which might have influence on CSR engagement protocols. In this regard, two types of measures were used i.e. financial indicators, that includes: Return on Assets (ROA), Return on Equity (ROE) (Rahmanet al., 2014; Malik, 2014), Earnings Per Share (EPS) (Sweeney, 2009; Cyrus, 2013; Sadiqa, 2014), Return on Deposit (ROD) and size (Ehsan, 2012; Cornett, 2014). Second type of measure was based on proxy of liquidity i.e. Advances/Deposit (A/D)ratio; while both types of predictors were named as performance indictors (PIs). ROA was calculated as ratio of net income to the total assets, ROE as ratio of net income to common share holder's equity, EPS as net profit to number of shares outstanding, Size as Log of Total Assets (LOTA) (Ehsan, 2012).

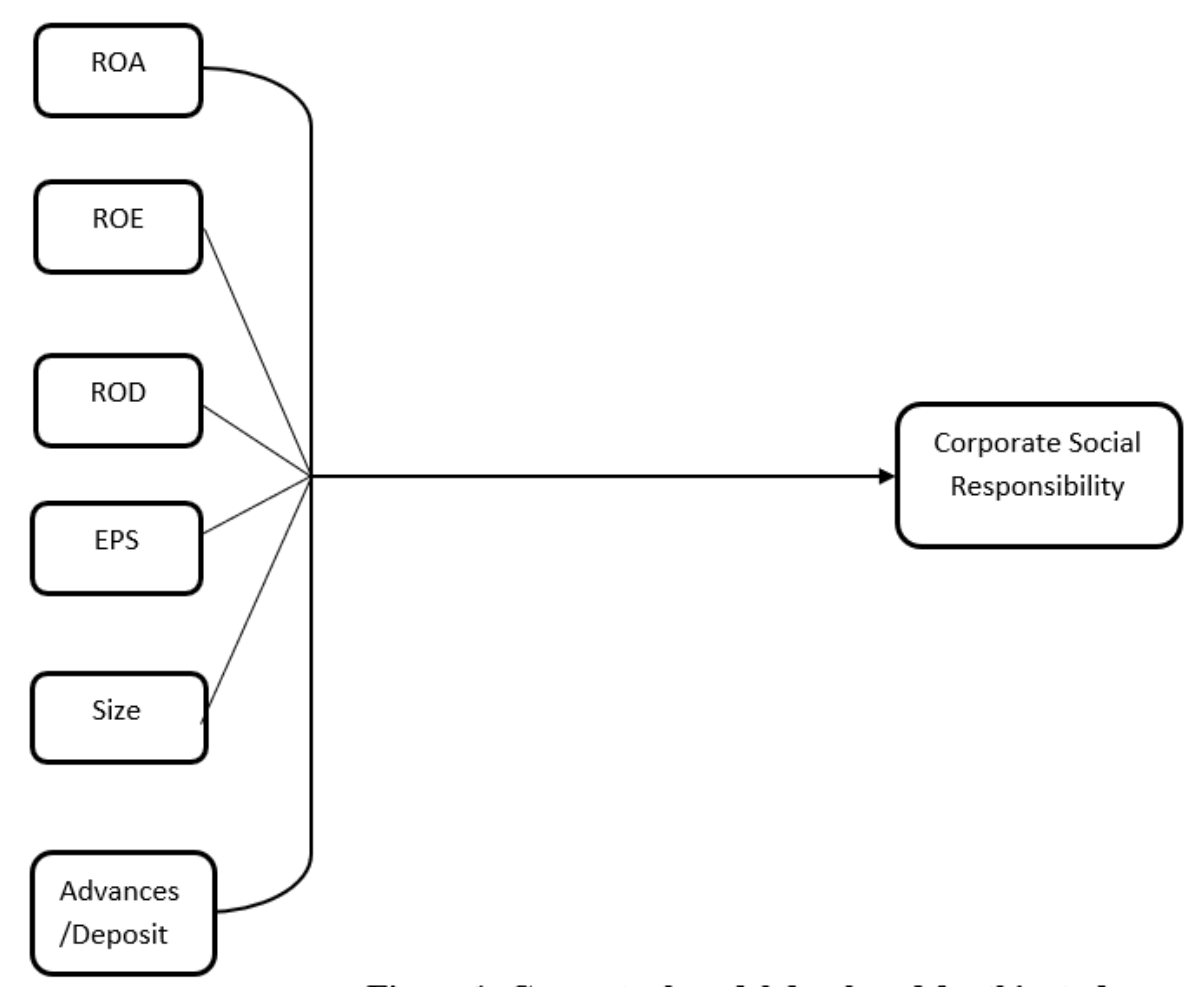

Figure 1: Conceptual model developed for this study

We developed following hypothesis to respond research preposition:

H1:Return on assets (ROA) has significant impact on CSR.

H2:Return on equity (ROE) has significant on CSR.

H3: Return on deposit (ROD)has significant impact on CSR.

H4:Earning per share (EPS) has significant impact on CSR.

H5:Size (of bank) has significant impact on CSR..

H6:Advance to deposit ratio (A/D ratio) has significant impact on CSR. 


\section{Model Specification}

In light of study conducted by Ehsan (2012), Generalized Least Square (random effect) regression on panel data was applied to test the relationship between CSR and performance indicators. For this purpose, six regression equations were developed to respond our hypotheses. In each equation, CSR was used as dependent variable; while financial and liquidity measures were used as independent variables. There were five proxies for financial performance ROA, ROE, ROD, EPS, and Size and one measure of liquidity performance i.e. A/D ratio was used for our proposed model:

1. $\mathrm{CSR}_{\mathrm{it}}=\beta_{\mathrm{o}}+\beta_{1} \mathrm{ROA}_{\mathrm{it}}+\varepsilon_{\mathrm{it}}$

2. $\mathrm{CSR}_{\mathrm{it}}=\beta_{\mathrm{o}}+\beta_{2} \mathrm{ROD}_{\mathrm{it}}+\varepsilon_{\mathrm{it}}$

3. $\mathrm{CSR}_{\mathrm{it}}=\beta_{\mathrm{o}}+\beta_{3} \mathrm{ROE}_{\mathrm{it}}+\varepsilon_{\mathrm{it}}$

4. $\mathrm{CSR}_{\mathrm{it}}=\beta_{\mathrm{o}}+\beta_{4} \mathrm{EPS}_{\mathrm{it}}+\varepsilon_{\mathrm{it}}$

5. $\quad \operatorname{CSR}_{\text {it }}=\beta_{\mathrm{o}}+\beta_{5}$ Size it $+\varepsilon_{\text {it }}$

6. $\mathrm{CSR}_{\text {it }}=\beta_{0}+\beta_{6} \mathrm{~A} / \mathrm{D}_{\mathrm{it}}+\varepsilon_{\mathrm{it}}$

\section{Results and Discussions}

Financial data of 11 banks were taken for 10 years (2004 to 2013) and there were 770 observations in the sample panel data. Table 1 represents the correlation matrix between performance indicators namely ROA, ROE, ROD, EPS, Size, A/D ratio and CSR.

Table1: Correlation among Predictors and CSR

\begin{tabular}{|c|c|c|c|c|c|c|c|c|}
\hline & & ROE & ROD & EPS & Size & $\mathrm{A} / \mathrm{D}$ & ROA & CSR \\
\hline ROE & $\begin{array}{c}\text { Pearson } \\
\text { Correlation }\end{array}$ & 1 & $.520^{* * *}$ & $.503^{* * *}$ & -.027 & $.261^{* * *}$ & .098 & $-.377^{* *}$ \\
\hline & Sig. (2-tailed) & & .000 & .000 & .779 & .006 & .313 & .000 \\
\hline ROD & $\begin{array}{c}\text { Pearson } \\
\text { Correlation }\end{array}$ & & 1 & $.635^{* * *}$ & -.128 & $.201^{*}$ & .150 & $-.292^{* * *}$ \\
\hline & Sig. (2-tailed) & & & .000 & .184 & .036 & .120 & .006 \\
\hline EPS & $\begin{array}{c}\text { Pearson } \\
\text { Correlation }\end{array}$ & & & 1 & -.047 & .054 & .017 & -.097 \\
\hline & Sig. (2-tailed) & & & & .622 & .574 & .859 & .373 \\
\hline Size & $\begin{array}{l}\text { Pearson } \\
\text { Correlation }\end{array}$ & & & & 1 & $-.252^{* * *}$ & -.044 & -.052 \\
\hline & Sig. (2-tailed) & & & & & .008 & .647 & .636 \\
\hline $\mathrm{A} / \mathrm{D}$ & $\begin{array}{c}\text { Pearson } \\
\text { Correlation }\end{array}$ & & & & & 1 & -.022 & -.120 \\
\hline & Sig. (2-tailed) & & & & & & .817 & .267 \\
\hline ROA & $\begin{array}{c}\text { Pearson } \\
\text { Correlation }\end{array}$ & & & & & & 1 & -.193 \\
\hline & Sig. (2-tailed) & & & & & & & .073 \\
\hline CSR & $\begin{array}{c}\text { Pearson } \\
\text { Correlation }\end{array}$ & & & & & & & 1 \\
\hline
\end{tabular}


Table 1 depicts correlation results. Two out of six performance indicators i.e. ROE and ROD have shown negative and moderate relationship with CSR. However, no correlation was found between CSR and remaining four performance indicators i.e. EPS, size, A/D \& ROA. ROE was found to be positively and significantly related to EPS and ROD but moderately related to A/D. No association was found between ROE and bank size. ROD was found to be positively and significantly associated with ROE, EPS and moderately related to A/D. However, ROD was insignificantly related to ROA and bank size. EPS was found to be significantly and positively related to ROE and ROD but insignificantly to bank size, A/D and ROA. Size was found to be significantly and negatively related to A/D ratio but insignificant with all remaining five proxies of PIs. A/D ratio was found to be positively and moderately related to ROE and ROD but significantly and negatively related to bank size. A/D was found to be insignificantly related to all remaining variables. ROA was found to be insignificant to all others.

Table 2: Results of Generalized Least Square Random Effect Regression Analysis

\begin{tabular}{cccccc}
\hline Variables Name & C & Probability & t-Statistics & $\mathrm{R}^{2}$ & $\mathrm{DW}$ \\
\hline ROA & 0.04829 & 0.0848 & -1.73926 & 0.027399 & 1.418 \\
ROD & 0.07555 & 0.0057 & -2.81858 & 0.069044 & 1.453 \\
ROE & 0.09238 & 0.0001 & -4.085367 & 0.132115 & 1.600 \\
EPS & 0.05295 & 0.0446 & -2.0347 & 0.017428 & 1.416 \\
Size & -0.00051 & 0.5430 & 0.6101 & 0.003411 & 1.792 \\
Advance/Deposit & 0.089272 & 0.2388 & -1.1845 & 0.012792 & 1.395 \\
\hline
\end{tabular}

Table 2 represents results of Generalized Least Square Random Effect Regression Analysis by taking CSR as dependent variable, while six PIs as predictors. ROE was found to have positive impact on CSR (0.09238, p < 0.0001), which means that one percent change in ROE leads to 9.238 percent change in bank's CSR. Coefficient of determination $\left(\mathrm{R}^{2}\right)$ for regression equation 3 waso.132115, which means that about $13.21 \%$ variation in CSR was because of ROE. When ROE was used as an independent variable to measure financial performance, the Random Effect (RE) was found pronounced in comparison of Fixed Effect (FE) since the results of Hausman test were insignificant (Ehsan, 2012; Wuand Shen, 2013; Sadiqa, 2014; Malik, 2014).ROD was found to have positive impact on CSR (0.0755, $\mathrm{p}<0.0057)$, which means that one percent change in ROD leads to 7.55 percent change in bank's CSR.

Coefficient of determination $\left(\mathrm{R}^{2}\right)$ for regression equation 2waso.069044, which means that about $7 \%$ variation in CSR was because of ROD. When ROD was taken as an independent variable to measure financial performance, the Random Effect (RE) was found to be pronounced in comparison of Fixed Effect (FE) since the results of Hausman test were insignificant. EPS was found to have positive impact on CSR (0.05295, $\mathrm{p}<0.0446)$, which means that one percent change in EPS leads to 5.29\% percent change in bank's CSR. Coefficient of determination $\left(\mathrm{R}^{2}\right)$ for regression equation 4waso.017428, which means that about $1.75 \%$ variation in CSR was because of EPS. When EPS was used as an independent variable to measure financial performance, the Random Effect (RE) was found to be pronounced in comparison of Fixed Effect (FE) since the results of Hausman test were insignificant. ROA, size and A/D predictors were found to have insignificant impact to CSR, which support the previous studies of (Ehsan, 2012; Wua, 2013; Sadiqa, 2014; Malik, 2014).

\section{Validation of Results through Personal Interviews}

Based on results of five profitability and one liquidity proxies of PIs, it was surfaced that three proxies namely ROE, EPS and ROD were found to be positively related to CSR. However, no relationship was found among CSR, ROA, ROD and A/D ratios. For validation of the above quantitative results, we used qualitative method and conducting semi structured interviews 
from partial respondents. The calibrated contents of personal interviews were used to specifically probe the logical reasoning of uneven quantitative results.

Every executive interviewed was well versed with concept of CSR from large to medium banks which is a reflection of bank's involvement with CSR. All executives were agreed that CSR is implemented in their banks. Few banks were found, which were following the CSR practices as policy like in response to a question regarding CSR being part of day to day activities, an executive said;

'We lend mainly to those corporate borrowers who are CSR compliant, free from child labor, having modernized plant \& machinery which is fuel efficient and environment friendly.'

Another senior credit analyst of a medium bank said:

'We duly document all the facts of loan seeking entity. As a matter of policy, we prefer to grant loan to manufacturing sector over trading sector. Focus of the bank is to generate economic activity with minimal pollution in order to welfare the masses.'

However on other hand, an executive serving as a Branch Manager in a medium sized bank said

'The service we provide to the customers is our duty/obligation; however, when we talk about CSR, this is not an obligation on banks but a voluntary activity performing by the banks.'

Surprisingly, it is surfaced from the personal interviews that terms of charity and CSR activities were interchangeably used. CSR policies used in Pakistani context lack the notion of considering CSR as a vital component for business success strategy and standardized CSR rules.CSR complaint entities find it more comfortable to attract new employees and retain existing ones.

It is also extracted from the interviews that the level and extent of CSR activities vary from bank to bank due to its volunteer nature. Mostly, no dedicated teams are performing CSR activities but surprisingly, these activities are generally conducted by media and advertising teams in the banks. From regulators perspective, it is appreciable to make it mandatory for banks to contribute in CSR activities to a certain extent with a well-defined policy, duly approved by Board of Directors. More than 50\% of the interviewed executives were considered that reasonable time and money is invested by banks on CSR activities; while other 50\% executives were not sure on this fact. One of the unsure respondent executive was explained the following factuality:

'No, enough time and money is not invested in CSR. CSR is more used as a marketing tool to attract more customers. It's not truly directed to welfare of employees or masses at large.'

The personal surveys unleashed the reality that CSR is not gaining momentum in Pakistan particularly in banking sector. This is due the fact that CSR activities are mainly used as marketing tool which is directed to win media campaign among banks instead of delivering true welfare substance for the masses. Another issue with CSR activities is that these activities are directed mainly to society at large to attract external customers, while ignoring internal customer i.e. employees of the bank. This is against the reality that only external customers are not the sole factor to add profitability, but these are internal customers as well, who are instrumental in generating good returns and creating goodwill of the organization. This reality truly exercised in a way that a blend of loyal internal and external customers is optimal to achieve performance milestones set by the banks.

Six out of eleven executives when questioned about impact of CSR activities on banks' performance indicators particularly financial indicators, they said:

'Yes, CSR really impacts the financial performance of the banks'. 
While five executives on the other side rightly rejected the preposition that CSR activities have impact on performance of the bank. They attributed continuing assured profits towards size, large branch network, innovative products, loyal customer, government deposit, government salary accounts, trust edimage, established repute etc. This is concisely inferred from the interviews that CSR is considered as a mere notional activity for stakeholders and published part of directors' report. Whether they invest in CSR activities or not, irrespective of this fact, banks are earning profit for the last many decades and will continue to do so.

\section{Conclusion}

CSR activities particularly with reference to Pakistani banking industry were tested and analyzed with respect to PIs comprised of financial and liquidity measures. For this investigation, PIs were used as predictors and CSR was used as endogenous variable. Six different PIs were used, out of which five were financial performance indicators (ROA, ROE, ROD, EPS, Size), while one was liquidity performance i.e. A/D ratio. In light of the analysis, it was surfaced that CSR is affirmatively related to ROE, EPS and ROD. Our results supported the recent studies of(Ehsan, 2012; Wua, 2013; Sadiqa, 2014; Malik, 2014).On the contrary, ROA and A/D ratios were found irrelevant with CSR engagement as indicated by previous studies of (Aras, 2009; Lin \& Chin-Huang, 2009; Soana \& -Gaia, 2011). Tovalidate the results, semi structured interviews were conducted with executives of sampled banks to base the results on concrete evidences.

Through interviews, it was surfaced that CSR is in infancy stage in Pakistan and there is a dire need to harmonize society requirements with CSR programs instead to continue their current strategy in which most of the banks merely take up CSR activities just to fulfill the legal requirement and/or published in annual audit accounts to build positive and strong signaling for stakeholders. It is also inferred from the surveys that in most of the banks, policies on CSR are unclear and lack strategic direction to be implemented for the benefits of internal and external customers. Often, CSR activities are confused with charity. Banks are indulging in CSR activities as a mere promotional tool which requires immediate return. Awareness on true model of CSR is lacking in banks as well as on consumer side. Large banks are earning profit and seem to continue their earnings irrespective of their CSR activities level. This is due to the fact of such banks' expanded asset base, more loyal customer base, branch network penetration, deposit segmentation etc.

Further, almost all banks are CSR complaint theoretically; however, in spirit practical implementation is yet to be done. CSR competitive environment among banks are required to encourage more banks to be CSR complaint and in turn occupy more market share on the basis of enhanced corporate image. No dedicated departments are formed to immensely look after CSR activities, the time and money required to be spent on CSR is not being spent. No particular guidelines are issued by regulators to cater CSR framework implementation and its continuous monitoring. Well defined policy and thorough legislation is lacking by government to identify underdeveloped avenues for the welfare of masses and economic progress of country. These CSR activities not only improve and enhance the corporate image of the bank but turn out as long term investments, which ultimately boost customer's loyalty and human resource commitment. This long term investment in form of CSR can impact the performance of banks positively.

Growing and prosperous banking sector, which constitute almost one third of the financial sector in Pakistan shall help country to achieve economic and financial independence. Countries whose banking system is profitable can effectively manage the financial distress and make a healthier input in the consistency of financial system. 'Action speaks louder than words' is a time needed requirement for CSR and it's true implementation in Pakistan as enough has been 
debated, discussed and researched now. It is more appropriate to take practical steps for its implementation by all stakeholders involved in CSR, the place is here and the time is now.

\section{1 Recommendations}

Going forward, based on our results, following steps are recommended for factual implementation of CSR framework in banking sector of Pakistan.

- Banks need to make a clear cut policy on CSR, along with plans to follow and its alignment with bank's strategic plan. CSR framework should be considered as key element for achievement of long term plans of the banks.

- Banks may not use CSR activities with sole signaling objective for marketing and promotion. Rather CSR activities should be initiated with full commitment and zeal for betterment of internal and external customers and society at large.

- Regulators are required to issue transparent guidelines to cater requirement of CSRframe work in banks for its implementation and ongoing monitoring.

- Government, through legislation and a well-designed policy, identify different arenas to be focused, which will help in economic and social welfare of all stakeholders and masses at large. CSR activities should be focused towards development of rural population, employment opportunities, infrastructure developments, provision of basic health facilities in remote areas, bio gas energy projects, clean drinking water, sanitation systems, vocational training institute etc. to be funded from profit oriented banks as their corporate and social responsibility for the society as a whole. Willing banks should be identified and government through mutual consensus, and they should assigns various projects as per their budget allocation to CSR activities.

- Government should also launch awards for CSR complaint banks to encourage peer banks to take vigilant part in it and give consumers a chance to choose from a list of CSR complaint banks in turn increasing their performances. Further, government should launch awareness campaigns through electronic and print media for creating awareness of banks as well as individuals on CSR rights and obligations.

\subsection{Future Research Directions}

Due to unique distinguish features; a comparison is recommended between Islamic and conventional banks to get more précised results. Future study can be imitated for Islamic banks exclusively with different set of performance indicators. The scope of future study can be further expanded to include foreign banks operating in different countries to form a comparative study to more generalize results. 


\section{References}

i. Abbas, A., Zaidi, S. A. H., Ahmad, W. \& Ashraf, R., 2014. Credit Risk Exposure and Performance of Banking Sector of Pakistan. Journal of Basic and Applied Scientific Research, 4(3), pp. 240-245.

ii. Aras, G., 2009. Investigating the relationship between corporate social responsibility and financial performance in emerging markets. International Journal of Productivity and Performance Management, 59(3), pp. 229 - 254.

iii. Cornett, M. M., 2014. CSR \& its impact on Financial Performance Investigation of US commercial Banks. [Online]

Available at: https://www2.bc.edu/ tehranih/CSR-Performance\%20Relationship \%20for\%20Banks\%20Jan\%202014.pdf.pp.1-53

iv. Ehsan, S., 2012. An Empirical investigation of the relationship between Corporate Social Responsibility and Financial Performance. Journal of Basic and Applied Scientific Research, 2(3), pp. 2909-2922.

v. Friedman, M., 1962. Capitalism and Freedom. 2nd ed. Chicago: University of Chicago.

vi. Khanifar, H., Nazari, K., Emami, M. \& Soltani, H., 2012. Impacts corporate social responsibility activities on company financial performance. Interdisciplinary Journal of Contemporary Research in Business, 3(9), pp. 583-592.

vii. Kim, M., 2011. Motivation for engaging in CSR Reporting: Comparative Study among Different Industries in Sweden, s.l.: Stockholm University.

viii. Makki, M. M. \& Lodhi, S., 2008. Determinants of Corporate Philanthropy in Pakistan. Pakistan Journal of Commerce and Social Sciences, Volume 1, pp. 17-25.

ix. Mushtaq, N., 2013. Paramount role of corporate social responsibility in retaining employees and corporate reputation: an extract from Pakistan's banking sector. Journal of Business and Finance, 1(3), pp. 126-138.

x. Rahman, M., Rashid, M. \& Haque, M.,-2014. Corporate Social Responsibility and Financial Performance: A Case Study of Jamuna Bank Limited,Bangladesh. Asian Journal of Finance \& Accounting, 6(2), pp. 351-361.

xi. Singh, M. \& Ahmed, S., 2015. Understanding CSR Practices in India. International Journal of Multifaceted and Multilingual Studies, 1(4), pp. 1-8.

xii. Srisuphaolarn, P., 2013. From altruistic to strategic CSR: how social value affected CSR development - a case study of Thailand. Social Responsibility Journal, 9(1), pp. 56-77.

xiii. State Bank of Pakistan, 2008. Strategy Paper. 10 years Strategy Paper. [Online] Available at: www.sbp.org.pk.

xiv. Surroca, J., 2009. CORPORATE RESPONSIBILITY AND FINANCIALPERFORMANCE: THE ROLE OF INTANGIBLE RESOURCES, Boston: Boston University.

xv. Sweeney, L., 2009. A Study of Current Practice of Corporate Social Responsibility (CSR) and an Examination of theRelationship Between CSR and Financial Performance Using Structural Equation Modelling, Dubline,Ireland: Dublin Institute of Technology.

xvi. Yeung, S., 2011. The Role of Banks in Corporate Social Responsibility. Journal of Applied Economics and Business Research, pp. 103-115.

xvii. Yusoff, A. W. \& Dahalan, D., 2011. An Ardl Approach To The Determinants Of Nonperforming Loans.. Kuwait Chapter of Arabian Journal of Business and Management Review, 1(2), pp. 33-47.

xviii. Zribi, N. B. Y., 2011. The factors influencing bank credit risk: The case of Tunisia. Journal of Accounting and Taxation, Vol. 3(4), pp. 70-78. 